www.jmscr.igmpublication.org Impact Factor 5.244

Index Copernicus Value: 83.27

ISSN (e)-2347-176x ISSN (p) 2455-0450 crossref DOI: _http://dx.doi.org/10.18535/jmscr/v4i9.51

\title{
Broadly Neutralizing Antibodies: The Path towards Universal Vaccines
}

Authors

\author{
Dr Hrishikesh Kashyapa ${ }^{1} *$, Dr Laxman Verma ${ }^{2}$, Dr Rupali B. Jadhav ${ }^{3}$ \\ ${ }^{1,2,3}$ Dept. of Pharmacology, Dr. V.M.G.M.C., Solapur-413003, Maharashtra, India \\ *Corresponding Author \\ Dr Hrishikesh Kashyapa
}

Flat no. 9, Mangal Residency phase-2, Asara chowk, Solapur, Maharashtra-413003

Email: hkashyapa@yahoo.co.in, Mobile No.: +919921449181

\begin{abstract}
Active and passive immunization to prevent Influenza virus and Human Immunodeficiency Virus-1 (HIV-1) infection has long been considered a potential treatment modality. Earlier efforts were largely unsuccessful as the antibodies studied neutralized only a narrow spectrum of viral strains. However, recent discovery of a large portfolio of human monoclonal antibodies that are broadly neutralizing across many HIV-1 subtypes and influenza strains has laid the foundation for such immunization strategies with universal vaccines being the ultimate aim. These antibodies target multiple different epitopes on the HIV envelope and influenza glycoprotein, thus neutralizing a broad range of viral variants. In this review, the role of broadly neutralizing antibodies (bNAb) in HIV and Influenza infection will be discussed along with their potential for use in developing structure based universal vaccines.

Keywords: broadly neutralizing antibodies, structure based vaccine, universal vaccine.
\end{abstract}

\section{Introduction}

The ability to effectively prevent infection by viruses which harbor high levels of antigenic variability, such as Influenza virus and Human Immunodeficiency Virus-1(HIV-1), has proven to be a difficult task. ${ }^{1}$ Infection with either virus leads to the induction of abundant strain-specific antibodies that are easily evaded by subsequent 'escape variants'. 2 To date, much of the considerable challenge involved in using neutralizing antibodies or antiviral agents to block virus infection can be attributed to the rapid changes in the immunogenic head of the viral glycoproteins, hemagglutinin of influenza and Env of HIV-1. More recently, researchers have turned to the identification and utilization of broadly neutralizing antibodies (bNAb), which bind to highly conserved neutralization epitopes and thereby neutralize a broad range of viral variants. Not only can bNAb be administered to patients as a form of passive immunotherapy, but they can also potentially be used for the rational design of universal vaccines. ${ }^{1}$

\section{Isolation of bNAbs and structure-based vaccine design}

bNAb can be isolated from vaccinated patients, as well as from individuals who have been suffering from virus infection over a prolonged period of time or long after the infection cycle is complete $^{3,4,5}$ (Fig 1). 


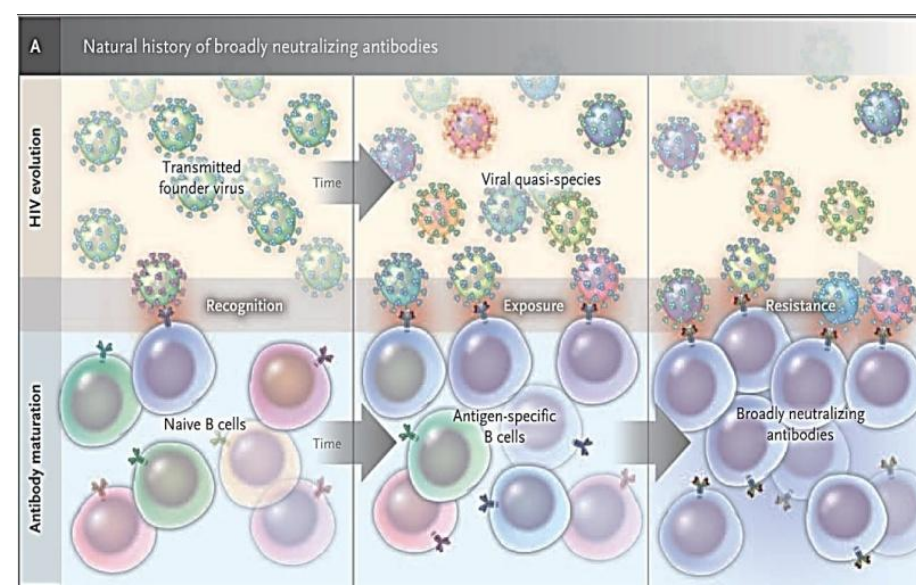

Fig 1: Early recognition of the transmitted virus by a naive $B$ cell (in blue) leads to the selection, expansion, and diversification of the antigenspecific population, followed by exposure to a rapidly diversifying viral quasi-species and leading to the generation of bNAbs. ${ }^{2}$

\section{Role of bNAbs in HIV infection}

In the case of HIV-1, it is the envelope protein Env, which produces the surface glycoproteins gp120 and gp41 responsible for virus entry into host cells. ${ }^{1}$ Though these glycoproteins tend to exhibit a high degree of sequence variability, they also possess conserved epitopes needed to maintain viral fitness. These epitopes are masked by sugar moieties (glycans) forging them into an evolving protective shield that prevents antibody binding. ${ }^{6}$ bNAbs can penetrate the glycan shield and bind to these conserved peptide sequences ${ }^{7}$ (Fig $2 \&$ Table 1).

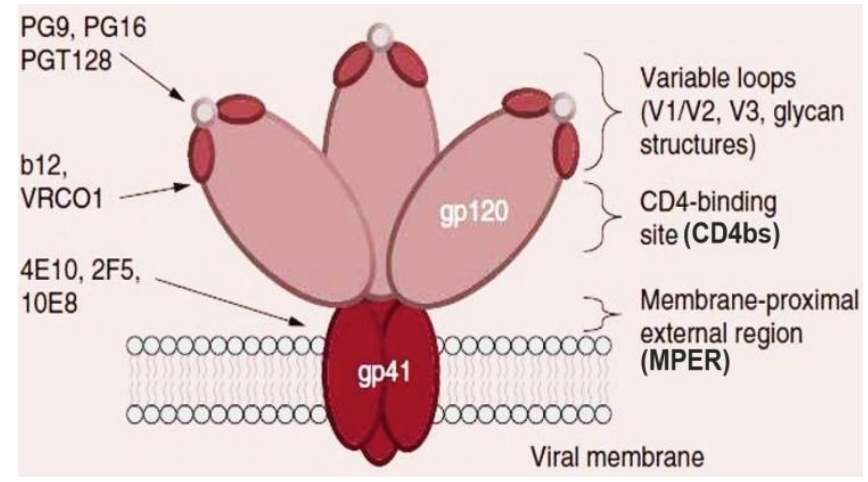

Fig 2: Currently, there are four broad classes of bNAbs against the HIV-1 trimeric spike: those that bind the gp41 MPER, gp120 V1/V2, V3 glycan and the gp120 CD4bs (prime target for the elicitation of bNAbs due to its high degree of conservation)
Table 1: Selected examples of bNAbs directed toward HIV-1.

\begin{tabular}{|c|c|c|}
\hline BNAb & Target site & $\begin{array}{l}\text { HIV isolates } \\
\text { neutralized }\end{array}$ \\
\hline PG9, PG16 & $\begin{array}{l}\text { gp120 variable loops } \\
\text { (V1/V2/V3) }\end{array}$ & $70-80 \%$ \\
\hline 4E10, 2F5, 10E8* & gp41 MPER & $98 \%$ \\
\hline b12, VRC01* & gp120 (CD4 binding sit) & $90 \%$ \\
\hline
\end{tabular}

Two to three years after infection, upto $25 \%$ of HIV-infected patients develop bNAbs which can neutralize $70-90 \%$ of all circulating HIV virus isolates. Co-crystallization of the bNAb with its epitope yields information regarding which exposed conserved regions or peptide sequences on the antigen can elicit an antibody response, and the epitope structure may help guide subsequent vaccine design containing a variety of epitope mimics $^{7}$ (Fig $3 \& 4$ ).

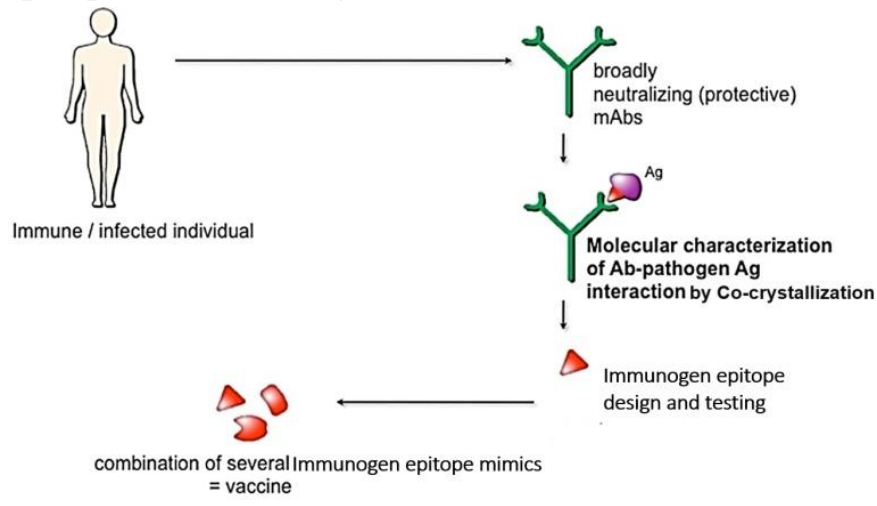

Fig 3: Structure based vaccine design for highly mutable pathogens

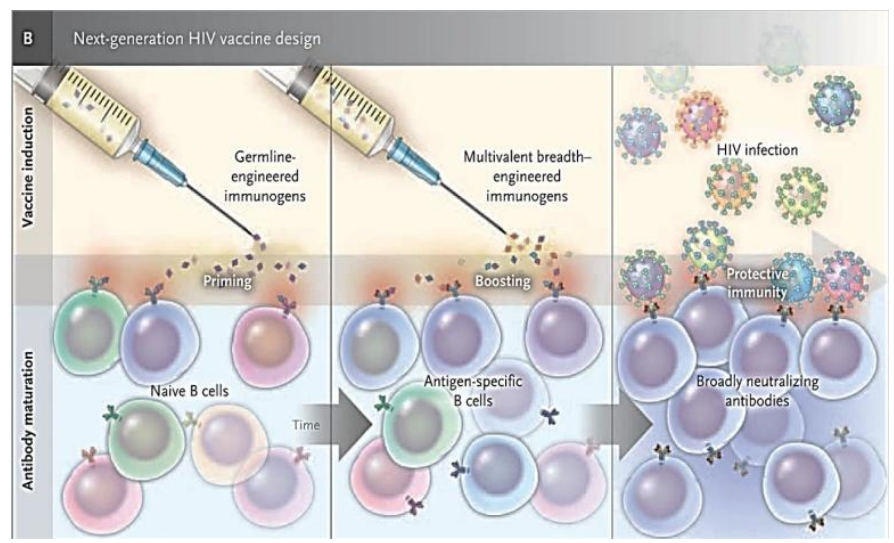

Fig 4: Immunogens could be designed to interact with naive B-cell receptors and coax B cells along specific maturation pathways. These B cells could then be boosted by designer envelope 
immunogens engineered to mimic the rapid diversification of the viral population and thereby accelerate the pace of B-cell selection and mutation - all of which would drive the induction of bNAb responses in the vaccinated subject. $^{2}$

\section{Role of bNAbs in Influenza infection}

In case of the influenza virus, the globular head of Hemagglutinin (HA) glycoprotein is subject to antigenic drift whereas the stem region is more conserved in structure. In most cases, neutralizing antibodies are targeted to the head domain and can result in the production of 'escape' mutants. $6,8,9$, bNAbs such as C179, 5A7, CR6261 and F10 target the conserved stem domain of the HA of influenza virus ${ }^{10,11}$ (Fig 5). These bNAbs show an unprecedented breadth of cross reactivity enabling them to neutralize many different strains within a subtype, group or even between groups and different types of influenza virus. ${ }^{12}$

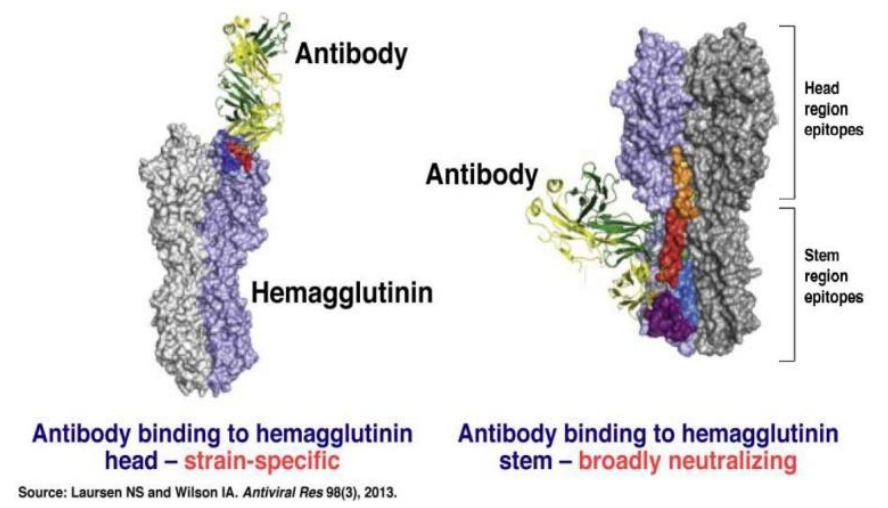

Fig 5: Binding of bNAb to HA stem.

\section{Conclusion}

It is clear from the steadily increasing number of bNAbs that have been identified and characterized, that the vision of universal vaccines is becoming increasingly realistic. After encouraging results in monkeys and mice in preventing HIV and influenza infections respectively, the next steps will involve human clinical trials, to fully demonstrate the potential of bNAbs as a substantial means to protect against all possible isolates of some the most difficult to control viruses known today.
Funding: None

Conflict of interest: None

\section{References}

1. Hefferon KL; Broadly. Neutralizing Antibodies and the Promise of Universal Vaccines Immunotherapy. 2014;6(1):5157.

2. Ackerman M. and Alter G; Mapping the Journey to an HIV Vaccine. The New England Journal of Medicine 2013 . 369;4

3. Mancini N, Carletti S, Perotti M et al. Phage display for the production of human mAbs against human pathogens. New Microbiol. 27(4), 315-328 (2004).

4. Walker LM, Burton DR. Rational antibody based HIV1 vaccine design: current approaches and future directions. Curr. Opin. Immunol. 22(3), 358-366 (2010).

5. Scheid JF, Mouquet H, Feldhahn $\mathrm{N}$ et al. Broad diversity of neutralizing antibodies isolated from memory $\mathrm{B}$ cells in HIV infected individuals. Nature 458, 636-640 (2009).

6. Kwong, P.D. et al. HIV-1 evades antibody-mediated neutralization through conformational masking of receptor binding sites. Nature 420, 678-682 (2002).

7. Kong L, Sattentau QJ (2012) Antigenicity and Immunogenicity in HIV-1 AntibodyBased Vaccine Design. J AIDS Clinic Res S8:003.

8. Clementi N, De Marco D, Mancini N et al. A human $\mathrm{mAb}$ with neutralizing activity against highly divergent influenza subtypes. PLoS ONE 6(12),e28001 (2011).

9. Yasugi M, KubotaKoketsu R. Human mAbs broadly neutralizing against influenza B virus. PLoS Pathog. 9(2),e1003150 (2013).

10. Ekiert DC, Wilson IA. Broadly neutralizing antibodies against influenza virus and prospects for universal therapies. Curr. Opin. Virol. 2(2), 134-141 (2012). 
11. Clementi N, Criscuolo E, Castelli $\mathrm{M}$, Clementi M. Broadrange neutralizing antiinfluenza A human mAbs: new perspectives in therapy and prophylaxis. New Microbiol. 35, 399-406 (2012).

12. Laursen, N. S., \& Wilson, I. A. (2013). Broadly neutralizing antibodies against influenza viruses. Antiviral research, 98(3), 476-483. 